\title{
Relationship between Drugs Use and Sexual Risk Behaviors among Senior High School Students
}

\author{
Yola Yuniaarti Herijanto, ${ }^{1}$ Lucky Saputra, ${ }^{2}$ Meita Dhamayanti ${ }^{3}$ \\ ${ }^{1}$ Faculty of Medicine Universitas Padjadjaran, ${ }^{2}$ Department of Psychiatry Faculty of Medicine, \\ Universitas Padjadjaran/Dr. Hasan Sadikin General Hospital Bandung, ${ }^{3}$ Department of Child \\ Health Faculty of Medicine, Universitas Padjadjaran/Dr. Hasan Sadikin General Hospital Bandung
}

\begin{abstract}
Background: Drugs use and risky sexual behavior among teenager are some of crucial problems arising in Indonesia. Statistic showed that there is an increasing prevalence in drugs use and risky sexual behavior among teenagers. This study was conducted to analyze the relationship between drugs use and risky sexual behaviors among high school students.

Methods: An analytic study involving 432 students in 5 state high schools located in Kerees region Bandung, West Java, Indonesia, was carried out in 2013. The region was chosen due the high prevalence of substance abuse. The inclusion criteria were every high school students in the Karees region. The exclusion criteria were the students who refused to participate in the study, did not come when the sample was taken, and did not fill the questionnaire completely. The instruments used for the study were questionnaires with crosssectional technique. Furthermore, the questionnaire used for analyzing drugs use was Addiction Severity Index-Lite Version (ASI-lite) questionnaire; with additional questionnaire to analyze risky sexual behaviors. Results: Out of 432 students, $23.8 \%$ students already engaged to one or more risky sexual behavior. Among all respondents, the prevalence of students who had already done kissing was $22.7 \%$, necking $9.3 \%$, petting $7.2 \%$ and sexual intercourse $1.2 \%$. Illegal drugs had been used at least once by $21.8 \%$ students. According to Chi-square test, drugs use and risky sexual behavior were related.

Conclusions:The prevalence of both drugs use and risky sexual behaviors are high and students who use drugs are more prone to do risky sexual behavior. [AMJ.2017;4(1):125-8]
\end{abstract}

Keywords: Drugs use, high school, sexual risk behavior

\section{Introduction}

Senior high school is a formal education for teenagers between the ages of 14 to $18 .{ }^{1}$ There are changes in many areas of life in a teenagers including physical, mental, emotional and social. Research showed that adolescences tend to use their emotional pathway rather than their cognitive pathway regarding to risk taking decision which lead them to do risky behavior. $^{2}$

Drug is any substance that has the ability to enhance physical or mental welfare. ${ }^{3}$ Drugs use among teenagers is one of the significant public health concerns. ${ }^{4}$ A survey conducted at Minnesota ${ }^{5}$ in 2011 showed that most of drugs users were 11-12 graders. Ricardo ${ }^{6}$ stated that the number of drug users was increasing. Many factors influenced drugs use, including family and peer pressure. ${ }^{4} \mathrm{~A}$ research conducted in
2012 showed that men with low education tend to be reported with negative alcohol abuse. ${ }^{7}$ According to the survey conducted on $2012,{ }^{8}$ for the last 5 years there was an increase of drugs use in teenagers less than 16 years old.

Prevalence of risky sexual behavior has also increased. A survey conducted in Ghana ${ }^{8}$ stated that 25\% teenagers admitted that they had done sexual intercourse, where males were at higher prevalence than females. According to the survey conducted by Survei Kesehatan Reproduksi Remaja Indonesia (SKRRI) on $2007,{ }^{9}$ the number of risky sexual behaviors committed by teenager was increasing. The term risky sexual behavior refers to any sexual behaviors that increase the risk of negative sexual consequences. ${ }^{10}$ Drugs use is believed to have an influence to the higher incidence of sexual risk behavior. ${ }^{11}$ Baldwin et al. ${ }^{12}$ stated

Correspondence: YolaYuniaarti Herijanto, Faculty of Medicine, Universitas Padjadjaran, Jalan Raya Bandung-Sumedang Km.21, Jatinangor, Sumedang, Indonesia, Phone: +6281294059673 Email: yolayuniaartiherijanto@gmail.com 
that alcohol consumption, cigarette smoking and illicit substance usage had an association with early sexual initiation. ${ }^{12}$ An analysis conducted by Ritchwood et al. ${ }^{13}$ stated that there was a positive association between drug use and risky sexual behaviors.

Considering the relationship between drugs use and risky sexual behavior among teenagers in Bandung City, it is likely to figure out the appropriate intervention to prevent a higher prevalence in the future. The aim of this study was to analyze the relationship between risky sexual behavior and substance abuse.

\section{Methods}

The survey was taken from October until November 2013. The participants involved in this survey were 453 senior high school students in Bandung City, West Java, Indonesia, located in Karees region. Karees region was chosen because of its high prevalence of substance abuse based on data from Grapiks, a non-government organization. This study used the non-paired categorical data analysis formula to obtain the minimal sample size. The minimal sample size of this study was 100 subjects. The inclusion criteria were every high school student in the Karees region who agreed to fill the questionnaire and presented at the data collection's day whereas, the exclusion criteria were students who refused to take part of the study, the students who did not come when the survey was taken, and the student who did not fill the questionnaire completely.

There were 453 students who came when the survey was taken. Of the 453 students, 21 students did not fill the questionnaire completely, therefore, they were excluded in the study. The questionnaire used in the study consisted of three parts: identity, sexual risk behaviors and substance-use. The prevalence of risky sexual behaviors was analyzed using questionnaire-containing questions to explore what kind of risky sexual behaviors done by the students.

The Addiction Severity Index Lite Version (ASI Lite Version) was used to identify the prevalence of substance use among the respondents. The ASI-lite is a shortened version of the Addiction Severity Index (ASI), an instrument used to analyze problem behaviors. The ASI-lite is a validated questionnaire which can be used to assess substances use and associated psychosocial impairment. ${ }^{14}$ After permitted by Health Research Ethics Committee of Faculty of Medicine, Bandung Municipal Government and Bandung Municipal Education Department, the questionnaires were administered to the schools. The questionnaires were administered to the selected schools. Before the questionnaires were administered to participants, the participants signed the inform consent and were given explanation to ensure the privacy of their identity and to explain the purpose of these questionnaires. The data were analyzed by statistical analysis.

There were 2 variables that were analyzed,

Table 1 Respondent Characteristics

\begin{tabular}{lccccc}
\hline & $\begin{array}{c}\text { Sexual Risk } \\
\text { Behavior* } \\
\text { n(\%) }\end{array}$ & $\begin{array}{c}\text { Drugs Use** } \\
\mathbf{n ( \% )}\end{array}$ & $\begin{array}{c}\text { Both } \\
\mathbf{n ( \% )}\end{array}$ & Not At risk & Total \\
\hline Age (Years) & & & & & \\
14 & $0(0)$ & $0(0)$ & $0(0)$ & $8(100)$ & 8 \\
15 & $15(15.6)$ & $15(15.6)$ & $9(9.4)$ & $75(78.1)$ & 96 \\
16 & $34(20.2)$ & $33(19.6)$ & $13(7.7)$ & $114(67.9)$ & 168 \\
17 & $52(34.2)$ & $44(28.9)$ & $26(17.1)$ & $82(53.9)$ & 152 \\
18 & $2(25.0)$ & $2(25.0)$ & $2(25)$ & $6(75.0)$ & 8 \\
Gender & & & & & \\
Male & $53(29.3)$ & $77(42.5)$ & $38(20.9)$ & $89(49.2)$ & 181 \\
Female & $50(19.9)$ & $17(6.8)$ & $12(4.8)$ & $196(78.1)$ & 251 \\
Total & $103(23.8)$ & $94(21.8)$ & $50(11.6)$ & $285(65.9)$ & 432 \\
\hline
\end{tabular}

Note: *Everyone except determined as "not having sexual risk behavior" by questionnaire, ${ }^{* *}$ Every drugs use regardless its substances 
YolaYuniaarti Herijanto, Lucky Saputra, Meita Dhamayanti: Relationship between Drugs Use and Sexual Risk 127 Behaviors among Senior High School Students

Table 2 The Prevalence of Drugs Use

\begin{tabular}{lcc}
\hline & Frequency & Percent (\%) \\
\hline Never use drugs & 338 & 78.2 \\
Use drugs at least once & 94 & 21.8 \\
Total & 432 & 100.0 \\
\hline
\end{tabular}

Table 3 Cross Tabulation between Drugs Use and Risky Sexual Behaviors

\begin{tabular}{lccc}
\hline & Risky sexual behaviors & $\begin{array}{c}\text { Not risky sexual } \\
\text { behaviors }\end{array}$ & Total \\
\hline Use drugs & 50 & 44 & 94 \\
Never use drugs & 53 & 285 & 338 \\
Total & 103 & 329 & 432 \\
\hline
\end{tabular}

and both of them were ordinal categorical variable. The independent variable was drugs use and the dependent variable was sexual risk behavior. Chi Square test was used to analyze the variables. To analyze whether the association was statistically significant, $\mathrm{P}$ value was calculated.

\section{Results}

From all respondents, 329 students (76.2\%) did not have any risky sexual behaviors and 103 students (23.8\%) did at least one risky sexual behavior. Furthermore, male students have higher risk (51.5\%) than females (48.5\%). Students who had the highest risk of doing risky sexual behaviors were $12^{\text {nd }}$ grade students $(53.4 \%)$, followed by $11^{\text {st }}$ grade students $(31.1 \%)$, and $10^{\text {th }}$ grade students (15.5\%). From all respondents, $22.7 \%$ students admitted that they had done kissing, $9.3 \%$ had done necking, $7.2 \%$ had done petting and $1.2 \%$ had done sexual intercourse. The youngest age of those students who had done kissing were less than 11 years old, necking were 13 years old, petting were 13 years old and sexual intercourse were 14 years old.

Among all respondents, 94 students $(21.8 \%)$ admitted that they had used drugs at least once; with the percentage of male students who used drugs which was much higher $(81.9 \%)$ than female $(18.1 \%)$. The most common type of drugs that were used by the students were nicotine $(66.2 \%)$, alcohol (23.3\%), marijuana (5.3\%) and methamphetamine $(1.5 \%)$. Barbiturate $(0.8 \%)$, cocaine $(0.8 \%)$, amphetamine $(0.8 \%)$, hallucinogens $(0.8 \%)$ and other drugs such as mushrooms $(0.8 \%)$ were the least drugs that were used by the students. The use of methadone and heroin were not found. The youngest age of nicotine user was 9 years old, alcohol user was 12 years old, marijuana user was 14 years old, methamphetamine user was 15 years old, barbiturate user was 14 years old, and amphetamine user was 13 years old. (Table 2).

Chi-square test was used to determine the relationship between drugs use and risky sexual behavior. Based on chi-square test, it can be concluded that there was an association between drugs use and risky sexual behavior, with $\mathrm{p}=0.001, \mathrm{OR}=6.111$ and $\mathrm{RR}=3.392$ (Table 3).

\section{Discussion}

The prevalence of risky sexual behaviors was much higher than the result obtained by Survei Kesehatan Reproduksi Remaja Indonesia (SKRRI) in 33 provinces of Indonesia on 2007 (4.1\%). ${ }^{9}$ The incidence of drugs use was also higher than the incidence of drugs use in a study conducted by SKRRI on 2007(3.4\%). ${ }^{6}$ This was caused by the sample size used in the survey was much bigger than the sample size used in this study.

The higher prevalence of risky sexual behaviors was also resulted from the different classification that the author used, where kissing, necking and petting were included to risky sexual behaviors category. ${ }^{10}$

The higher prevalence of drugs use may be caused by the difference of classification used by the author, in which Nicotine (cigarette) and Alcohol was included to addictive substances. ${ }^{3}$

The relationship between drugs use and high-risk sexual behaviors among teenager 
was in line to those reported by Doku in Ghanaian youth ${ }^{8}$ who stated that teenagers who used tobacco, alcohol and other drugs were found to increase the likelihood of doing risky sexual behaviors. An analysis conducted by Ritchwood et al. ${ }^{13}$ stated that there was a positive association between substance use and risky sexual behavior. Hipwell ${ }^{15}$ also stated that alcohol use increased the number of risky sexual behaviors among adolescents. This relationship can be explained as follows: drugs use can disturb brain development in teenagers which cause dysfunctions in cognitive and behavioral aspects. This dysfunctions will promote teenagers to do risk taking behaviors. ${ }^{12}$

The limitations of the study were the limited time for the author to conduct this study so that the data presented in this study was not normally distributed. Many factors that influenced of drugs use and risky sexual behaviors such as peer pressure and family influence 4 were not analyzed, which could be confounding factors in this study. The honesty of the respondents might be one of bias that could be found in this study, although the author had tried to minimize it by assuring the respondents of their secrecy.

The author suggested the usage of interview as an instrument rather than questionnaire to guarantee the honesty of the respondents. Other variables such as peer pressure, family and emotional condition can be analyzed to prevent confounding factors. The author also suggested using more samples in order to obtain the more significant result.

As a conclusion, the prevalence of risky sexual behaviors and drugs use among the high school students was high, and there was a significant association between drug use and risky sexual behaviors.

\section{References}

1. WhitelockP,Heuboeck A. Oxford dictionary. Oxford: Oxford University Press; 2013.

2. Smith AR, Chein J, Steinberg L. Impact of socio-emotional context, brain development, and pubertal maturation on adolescent risk taking. Horm Behav. 2013;64(2):323-332

3. WHO. Lexicon of alcohol and drug terms. Geneva: WHO; 1994 [cited: 2014 February 10]. Available from: http://apps.who.int/iris/ itstream/10665/39461/1/9241544686_ eng.pdf.

4. Branstetter SA, Low S, Furman W.
The influence of parents and friends on adolescent substance use: a multidimensional approach. J Subst Use. 2011;16(2):150-60.

5. Arcan C, Kubik MY, Fulkerson JA, Hannan PJ, Story M. Substance use and dietary practices among students attending alternative high schools: result from a pilot study. BMC Public Health. 2011;11:263-72

6. Ricardo P. Upaya penanggulangan penyalahgunaan narkoba oleh kepolisian (studi kasus satuan narkoba polres metro bekasi). Jurnal Kriminologi Indonesia. 2010;6(3):232-45.

7. Grittner U, Kuntsche S, Graham K, Bloomfield K. Epidemiology social inequalities and gender differences in the experience of alcohol-related problems. Alcohol Alcohol. 2012;47(5):597-605.

8. Doku D. Substance use and risky sexual behaviours among sexually experienced Ghanaian youth. BMC Public Health. 2012;12(1):571-8.

9. Lestary H, Sugiharti. Young adults risk behavior by Indonesia young adult reproductive health survey in 2007. Jurnal Kesehatan Reproduksi. 2011;1(3):136-44

10. Musthofa SB, Winarti P. The influencing factors of a pre-marital sexual behavior among college students in Pekalongan. Jurnal Kesehatan Reproduksi. 2010;1(1):33-41

11. Turner AK, Latkin C, Sonenstein F, Tandon SD. Psychiatric disorder symptoms, substance use, and sexual behavior among african-american out of school youth. Drug Alcohol Depend. 2011;115(1-2):67-73.

12. Baldwin P, Shrestha R, Potrepka J, Copenhaver M. Review article the age of initiation of drug use and sexual behavior may influence subsequent HIV risk behavior: a systematic review. ISRN AIDS. 2013;2013:976035.

13. Ritchwood TD, Ford H, DeCoster J, Sutton M, Lochman JE. Risky sexual behavior and substance use among adolescents: a meta-analysis. Child Youth Serv Rev. 2015;52:74-88.

14. Fiellin DA, Weiss L, Botsko M, Egan JE, Altice FL, Bazerman LB, et al. Drug treatment outcomes among HIV-infected opioid dependent patients receiving buphrenorphine/naloxone. J Acquir Immune Defic Syndr. 2011; 56(01):1-13.

15. Hipweel A, Stepp S, Chung T, Durand V, Keenan K. Growth in alcohol use as a developmental predictior of adolescent girls' sexual risk-taking. Prev Sci. 2012;13(2):118-28. 